\title{
Keratinocyte growth factor and beta-cell differentiation in human fetal pancreatic endocrine precursor cells
}

\author{
J. Movassat ${ }^{1,2}$, G. M. Beattie ${ }^{1}$, A. D. Lopez ${ }^{1}$, B. Portha ${ }^{1,2}$, A. Hayek ${ }^{1}$ \\ ${ }^{1}$ Islet Research Laboratory, Department of Pediatrics, University of California, San Diego Medical School, \\ La Jolla, California, USA \\ ${ }^{2}$ Laboratory of Nutritional Pathophysiology University of Paris, National Center of Scientific Research, Paris, France
}

\section{Abstract}

Aims and hypothesis. Keratinocyte growth factor (KGF) is a member of the heparin-binding fibroblast growth factor family with a high degree of specificity for epithelial cells in vitro and in vivo. Our aim was to study the effect of KGF on beta-cell growth and differentiation on islet-like cell clusters derived from human fetal pancreas.

Methods. We investigated the effects of KGF, in vitro, on beta-cell differentiation from undifferentiated pancreatic precursor cells and in vivo after transplantating human fetal pancreatic cells into athymic rats treated with KGF.

Results. Treatment of islet-like cell clusters with KGF in vitro did not change the number of insulin producing cells, as measured by the measurement of insulin content or DNA. The in vivo treatment of recipient rats with KGF increased the number of beta cells within the grafts 8 weeks after transplantation. At this time, glucose-stimulated insulin secretion was evaluated by glucose stimulation tests in rats bearing the transplants. Measurements of human C-peptide concentrations after glucose challenge showed that the newly differentiated beta cells in the KGF-treated group were functionally competent as opposed to the control group, where the graft failed to release insulin appropriately.

Conclusion/interpretation. These findings suggest that in vivo, KGF is capable of inducing human fetal beta-cell expansion. The growth promoting effect of KGF on beta cells occurred mainly through the activation of ductal cell proliferation and their subsequent differentiation into beta cells. [Diabetologia (2003) 46:822-829]

Keywords Pancreas, KGF, beta-cell differentiation, ductal cell proliferation.
Pancreatic growth and differentiation is controlled by intra and extra cellular signals acting in a paracrine or endocrine manner. Among the extracellular effectors, a variety of growth factors have been described to induce proliferation and/or differentiation of the differ-

Received: 18 December 2002 / Revised: 24 February 2003 Published online: 11 June 2003

C Springer-Verlag 2003

Corresponding author: A. Hayek MD, Islet Research Laboratory, Department of Pediatrics, University of California, San Diego Medical School, 9894 Genesee Ave., La Jolla, California 92037, USA

E-mail: ahayek@ucsd.edu

Abbreviations: ICCs, Islet-like cell clusters; KGF, keratinocyte growth factor. ent pancreatic endocrine-cell types namely beta cells, $\alpha$ cells, $\delta$ cells and PP cells. The Keratinocyte growth factor (KGF), also called FGF 7, is a member of the heparin-binding fibroblast growth factor family. The peptide, originally isolated from the conditioned medium of a human embryonic lung fibroblast-cell line [1] shows a high degree of specificity for epithelial cells. The keratinocyte growth factor has been identified as an important effector of epithelial growth and tissue homeostasis in various organs, including the gastrointestinal tract [2], dermis [3] and lung epithelia [4]. In the pancreas, KGF has been shown to stimulate ductal-cell proliferation [5]. The aim of our study was to examine the effect of KGF on the growth and differentiation of beta cells derived from the human fetal pancreas. 


\section{Materials and methods}

Human tissue. Human fetal pancreases used in these experiments were provided by Advanced Bioscience Resources (Oakland, Calif., USA) and The Central Laboratory for Human Embryology, University of Washington (Seattle, Wash., USA) after the termination of pregnancy by dilatation and extraction between 18 and 22 weeks of gestation. Informed consent for tissue donation was obtained by the procurement centre. In addition, our own institution review board reviewed and approved the use of fetal tissue for these studies.

Tissue preparation. Tissue was processed as described previously [6] by digestion with collagenase Type 11 (Sigma, St Louis, Mo., USA). After collagenase digestion of the pancreases, an equal amount of the suspension was transferred into $60 \mathrm{~mm}$ Petri dishes. In each experiment at least two Petri dishes were used as control group. Therefore, the islet-like cell clusters (ICCs) which formed in each dish after 2 to 3 days of culture were a mixture of several pancreases regardless of the fetal age.

The islet-like cell clusters were cultured in RPMI-1640 with $10 \%$ of the human serum. As characterized previously $[7,8]$, the islet-like cell clusters derived from fetal pancreases consist of about $12 \%$ endocrine cells with $5 \%$ beta cells and mostly undifferentiated epithelial cells.

$K G F$ treatment in vitro. The keratinocyte growth factor (Amgen, Thousand Oaks, Calif., USA) at the dose of $25 \mathrm{ng} / \mathrm{ml}$ was added to the culture media on the day of tissue processing and during the subsequent 7 days. Culture media was changed every 2 days and fresh KGF was added. Two of the culture dishes were used as control groups in each set of experiments.

Measurement of insulin and DNA content. For insulin extraction, the ICCs were hand picked using direct vision under a stereoscope, homogenized in distilled water and sonicated. Aliquots of the sonicates were extracted with acid/ethanol for insulin radioimmunoassay using a solid phase assay kit (DPC, Los Angeles, Calif., USA) as described previously [8], or dried for DNA quantitation by a fluorometric technique [9].

Transplantation experiments. The animals used in this study were Rowlett athymic nude rats obtained from Charles River Breeding Laboratories (Charles River, Mass., USA). They were housed in microisolater cages in a semisterile room. Animals were maintained according to the NIH Guide for the Care and Use of Laboratory Animals. ICCs formed in culture (1000/animal) were transplanted into nude rats under the kidney capsule using a positive displacement pipette as described previously [10].

KGF treatment in vivo. Rats were treated with KGF (Amgen, Thousand Oaks, Calif., USA) or saline solution for 10 consecutive days $48 \mathrm{~h}$ after transplantation. Keratinocyte growth factor or saline solution were administrated by intraperitoneal injection, once a day at the dose of $3 \mathrm{mg} \mathrm{KGF}$ per kg of body weight. This dose was found previously to ameliorate streptozotocin induced diabetes in Sprague Dawley rats [11]. Every day before injection, the rats were weighed and their blood glucose was measured, using a glucometer (One Touch, Lifescan, Milpitas, Calif., USA) on a blood sample collected from the tail vein.

Functional response. Eight weeks after transplantation, fasted rats were given glucose $3 \mathrm{~g} / \mathrm{kg}$ ip. Blood was withdrawn from the tail vein before glucose administration (T0) and $30 \mathrm{~min}$ after (T30) glucose administration. Samples were immediately centrifuged and plasma was stored at $-20^{\circ} \mathrm{C}$ until the measure- ment of human C-peptide concentrations using an RIA that does not cross-react with rat C-peptide (DPC, Los Angeles, Caloif., USA).

Grafts were removed $24 \mathrm{~h}$ after the glucose challenge and processed for histological analysis.

Immunohistochemistry and morphometry. Kidneys bearing the transplanted fetal ICCs were fixed in $4 \%$ paraformaldehyde, dehydrated, embedded in paraffin and sequentially sectioned. Graft sections were stained for insulin using the immunoperoxidase method as described previously [12]. A guinea pig anti porcine insulin (ICN Pharmaceutical, Orsay, France) was used as the primary antibody. Quantitative evaluation of total betacell area was done by using a computer-assisted image analysis procedure based on an Olympus BX 40 microscope connected via a video camera to a PC computer and using the Visiolab 1000 software (Biocom, Les Ulis, France). The area of insulinpositive cells, as well as the total graft area were evaluated in each stained section. The relative beta-cell area in the graft was determined by stereological morphometric methods, calculating the ratio between the area occupied by insulin positive cells and that occupied by the non-insulin positive cells in the graft. Within the sections, the graft area could be easily distinguished from the kidney tissue by morphological criteria. The relative beta-cell area in the pancreas of rats receiving the transplant was determined using the same stereological morphometric method. Due to the inherent heterogeneity in using primary fetal tissue and a possible difference in the number or the size of ICCs originally transplanted in each rat, we expressed the beta-cell area as the ratio of beta-cell area to the total graft area. This allows us to estimate the proportion of developing beta cells within the graft based on the original amount of human tissue transplanted in each rat. Therefore, variations in the number or the size of ICCs do not interfere with the evaluation of the number of beta cells present at the time of the study.

Beta-cell and ductal cell replication. To identify the dividing beta cells, a heat-induced epitope retrieval method was used to reveal the expression of human $\mathrm{Ki}-67$, a proliferation marker. Sections were boiled in citrate buffer pH 6.0 (Zymed Laboratories, San Francisco, Calif., USA). A mouse anti-human Ki-67 (Dako, Trappes, France) antibody was used as the primary antibody. The secondary antibody was a peroxidase conjugated goat anti-mouse IgG from Jackson Immunoresearch Laboratories (West Grove, Pa., USA). After Ki-67 staining, the tissue sections were washed in Tris- $\mathrm{HCl}$ and then the same sections were stained for insulin. Insulin staining was done by using a guinea pig anti-porcine insulin as primary and an alkaline phosphatase-conjugated rabbit anti-guinea pig IgG (Dako) as secondary antibody. To estimate the beta cell proliferating in the graft, insulin-positive cells and double-stained insulin/Ki-67 cells were counted using an Olympus BX40 microscope. Results were expressed as the percentage of $\mathrm{Ki}-67$ positive beta cells. At least 800 beta cells were counted per graft. On the same sections, the percentage of Ki-67 positive cells located in the ductal epithelium was also evaluated. During the growth and differentiation of the transplanted tissue under the kidney capsule, beside the islet-like structures containing the endocrine cells, there were also ductal elements developing in the graft. We evaluated the proliferation index of ductal cells by calculating the ratio of ductal cells stained for Ki-67 to the total number of cells forming the ductal structures within the graft.

Statistical analysis. Observed differences were analysed by Student's $t$ test. A $p$ value of less than 0.05 was considered significant. 


\section{Results}

In vitro study

To determine whether addition of KGF to the culture media alters beta-cell differentiation in fetal ICCs, we measured the amount of insulin within the ICCs treated with KGF as compared to the control cultures. After 7 days of KGF treatment the measurement of insulin content per DNA showed no significant differences between the two groups in four separate experiments $(1.11 \pm 0.2 \mathrm{pmol}$ insulin $/ \mu \mathrm{g}$ DNA in the KGF treated ICCs vs $1.13 \pm 0.16 \mathrm{pmol}$ insulin $/ \mu \mathrm{g}$ DNA in control cultures.)

\section{In vivo study}

Follow up of transplantation of human fetal ICCs. To determine whether KGFs alter weight gain and/or blood glucose concentration in the nude rats, the glycaemia and the evolution of body weight were followed during the course of the treatment. These two parameters were measured daily during the treatment and once a week during the following 6 weeks. There were no differences in the body weight of KGF treated rats as compared to the control rats. The mean blood glucose value during the course of the treatment was $3.79 \pm 0.038 \mathrm{mmol} / \mathrm{l}$ in KGF-treated rats and $3.79 \pm 0.12 \mathrm{mmol} / \mathrm{l}$ in control rats. The weight gain during the 10-day time course of the treatment was $28 \pm 1.04 \mathrm{~g}$ in the KGF-treated group and $35 \pm 6.5 \mathrm{~g}$ in the control group. Therefore KGF exerted no statistically significant effect on the body weight of treated rats.

Beta-cell function. To evaluate the functionality of the differentiated beta cells within the grafted ICCs we did a glucose stimulation test to measure insulin secretion in response to glucose. For this experiment, 8 weeks after transplantation of human fetal ICCs, rats were challenged with glucose given ip, at the dose of $3 \mathrm{~g} / \mathrm{kg}$ body weight.

To distinguish between endogenous rat insulin and that secreted by human beta cells in the transplant, human C-peptide was measured using an RIA that does not cross-react with rat C-peptide [13]. Before glucose administration, the basal concentrations of human C-peptide (reflecting the insulin concentrations) were similar in both groups. Thirty minutes after glucose administration, the C-peptide concentrations and hence the insulin secretion was stimulated as shown by the increase of human C-peptide concentrations in KGF treated $(p<0.05)$ rats whereas in the control rats, the concentrations of human C-peptide did not change in response to glucose (Fig. 1).

In addition we did a glucose stimulation test in KGF-treated and control rats, 4 weeks after the begin-

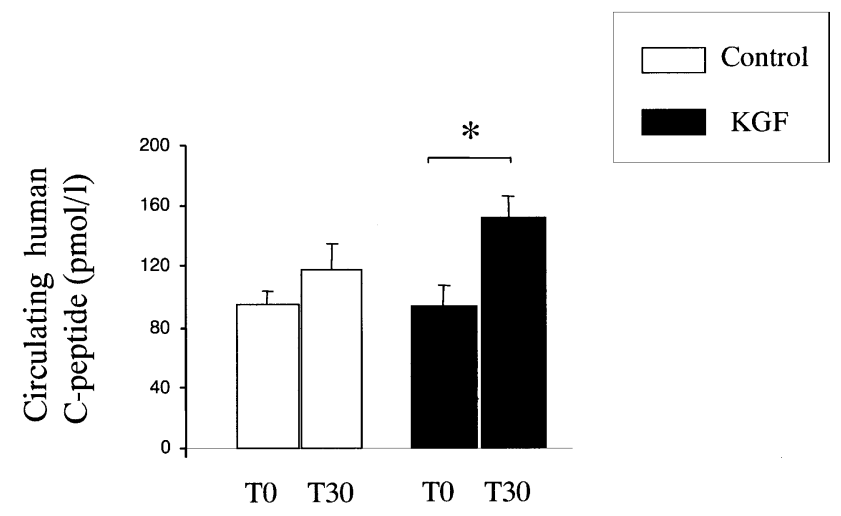

Fig. 1. Eight weeks after transplantation, circulating human C-peptide concentrations were measured before (T0) and 30 min after (T30) glucose challenge in fasted athymic rats treated with KGF (dark bars) $(n=5)$ or saline (white bars) $(n=4) . * P<0.05$ as compared to the human C-peptide concentrations in KGF-treated group before glucose administration (T0)

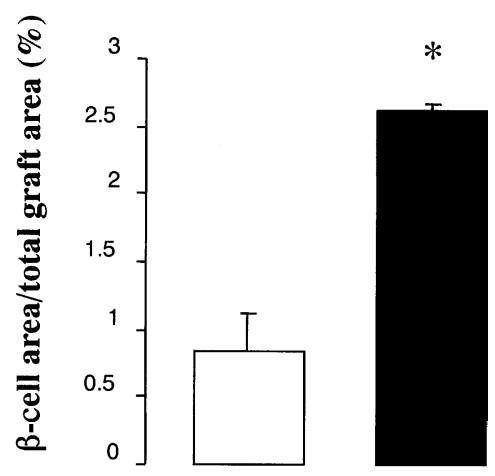

Fig. 2. Morphometrical analysis of the beta cells in grafts removed from KGF treated group (dark bar) ( $n=3)$ versus control group (white bar) $(n=5)$. A significant increase of the beta-cell area/total graft area was found in KGF-treated group compared to th control group. $* P<0.05$

ning of KGF treatment. The glucose-stimulated insulin secretion of human beta cells was already evident at this early stage in the KGF-treated group, whereas in the control group human fetal beta cells failed to respond to glucose. The stimulation index, calculated as the increase of human C-peptide concentrations 30 min after glucose administration was 1.7 in KGFtreated rats while no increase in C-peptide concentrations was observed in the control rats.

Beta-cell mass. To evaluate the effect of KGF on the expansion of beta-cell mass, we measured the betacell area within the graft by morphometry. The measurement of surface area occupied by insulin-positive cells in the grafts showed an increase in the transplants removed from the KGF treated rats compared to the control rats (Figs. 2, 3A,B).

To evaluate the effect of KGF treatment in the native islets in rats, we measured the relative beta-cell area within the pancreas of rats receiving transplants 

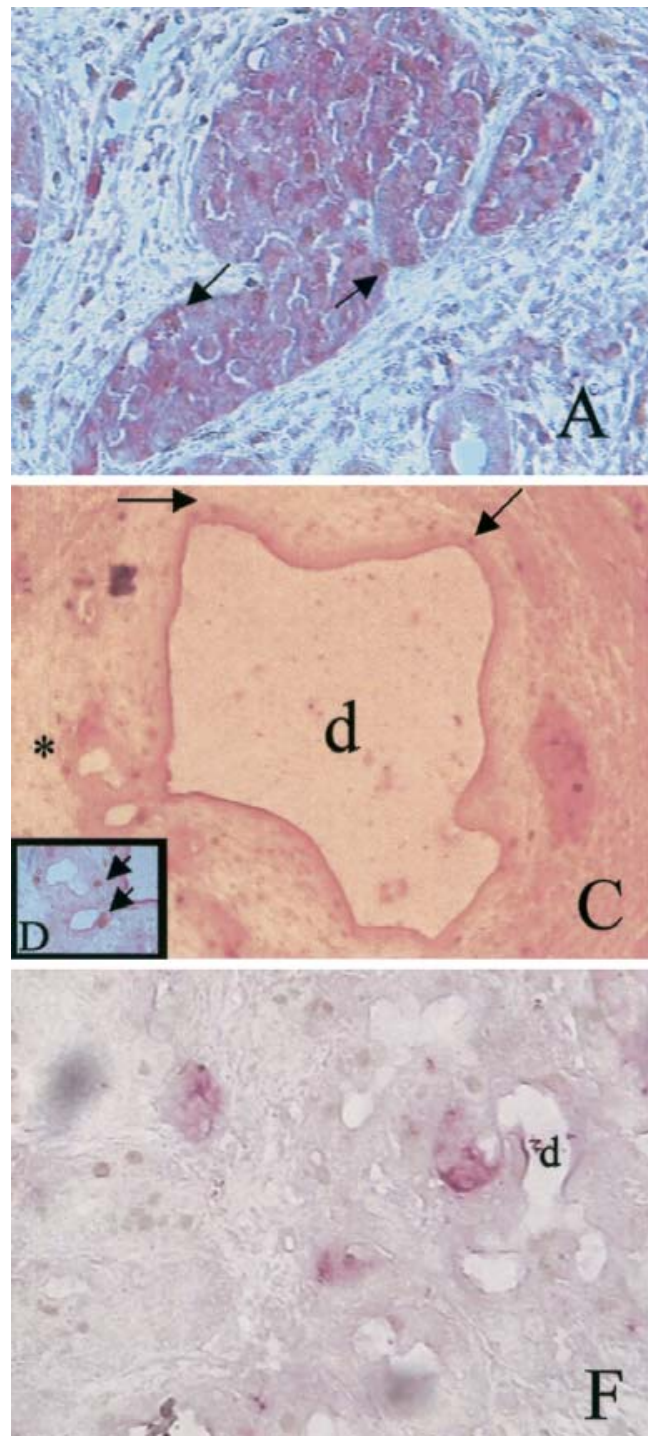

Fig. 3A-G. Immunostaining for insulin and Ki-67 in ICCs transplanted under the kidney capsule of athymic rats treated with $\mathrm{KGF}(\mathbf{A})$ or saline (B), during 10 days after the transplantation. Sections were immunostained for insulin by the alkaline phophatase method and for Ki-67 using the peroxidase method. Dividing cells exhibit brown nuclei. Beta cells show red cytoplasmic staining. Proliferating beta cells are identified as cells double-stained for insulin and Ki-67. Arrows show proliferating cells identified by Ki-67 staining. Photographs show the grafts 8 weeks after transplantation. Actual magnification: A and B x650. Ductal structures within the graft in KGF treated $(\mathbf{C}, \mathbf{D}$, E) and saline-treated control $(\mathbf{F}, \mathbf{G})$ rats. D Higher magnification of area depicted by asterisk in $\mathrm{C}$. The incidence of medium and large ducts was higher in KGF-treated graft compared to the controls. d: duct lumen. Arrows show proliferating ductal cells identified by Ki-67 staining. Actual magnification: $\mathrm{Cx} 325$; D, E, F, Gxx650

in both KGF and control groups. We found a slight increase in the beta-cell area per pancreas in the KGFtreated rats $(0.45 \pm 0.1 \%)$ compared to the control group $(0.25 \pm 0.03 \%)$, but this difference was not statistically significant.

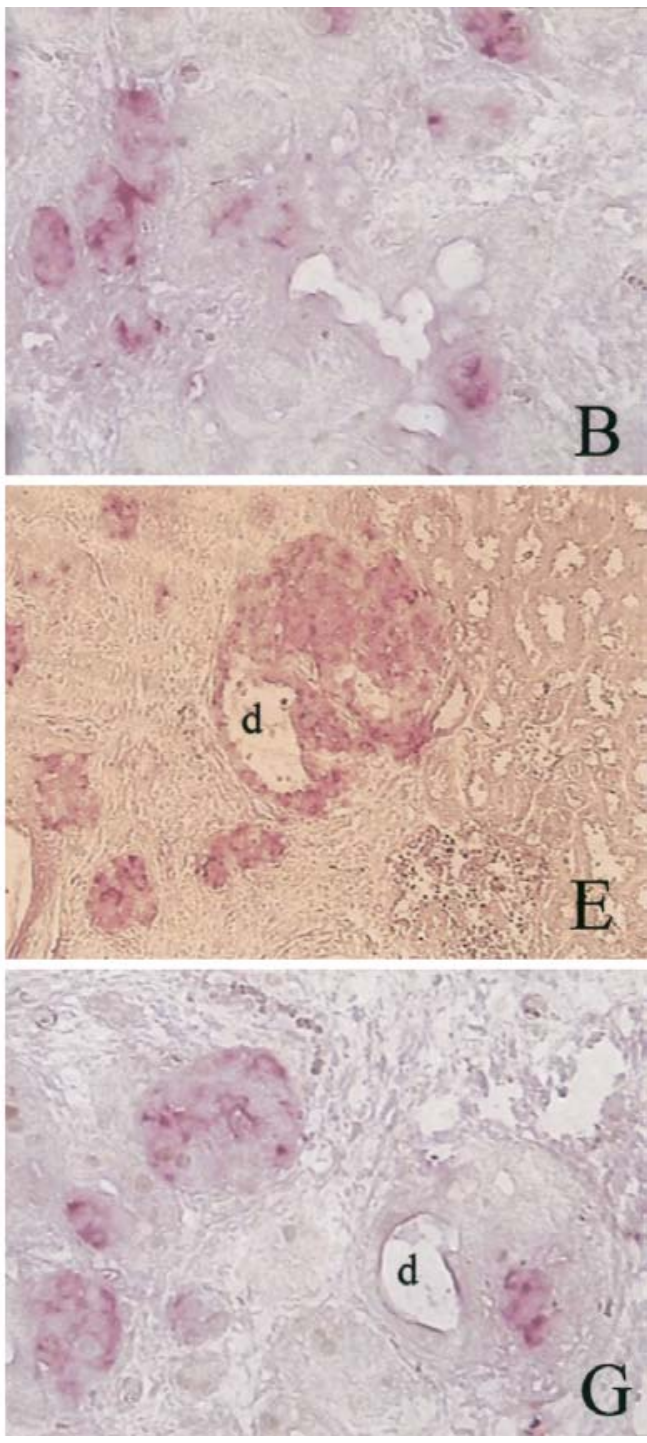

Effect of KGF on beta cell and ductal cell proliferation. We assessed the mitogenic effect of KGF on the grafted cells by Ki-67 immunostaining. The betacell proliferation index was measured by calculating the percentage of Ki-67 positive beta cells over the total number of beta cells in the graft. In the KGFtreated group, the rate of replicating beta cells was $1.98 \pm 0.8 \%$ of the total beta-cell number versus $2.1 \pm 0.6 \%$ in the control group (Fig. 4A). We also measured the percentage of ductal cells which showed Ki-67 staining in their nucleus. The percentage of proliferating ductal cells was $5.4 \pm 0.9$ in the KGF-treated group and $2.63 \pm 0.09$ in the control group. This increase $(p<0.05)$ indicates a mitogenic effect of KGF on human fetal ductal cells (Fig. 4B). Moreover, morphological examination of the graft sections showed a higher incidence of medium to large ductal structures (consisting of more than 30 cells) in KGF treated grafts as compared to the control group (Fig. 3C-G). 

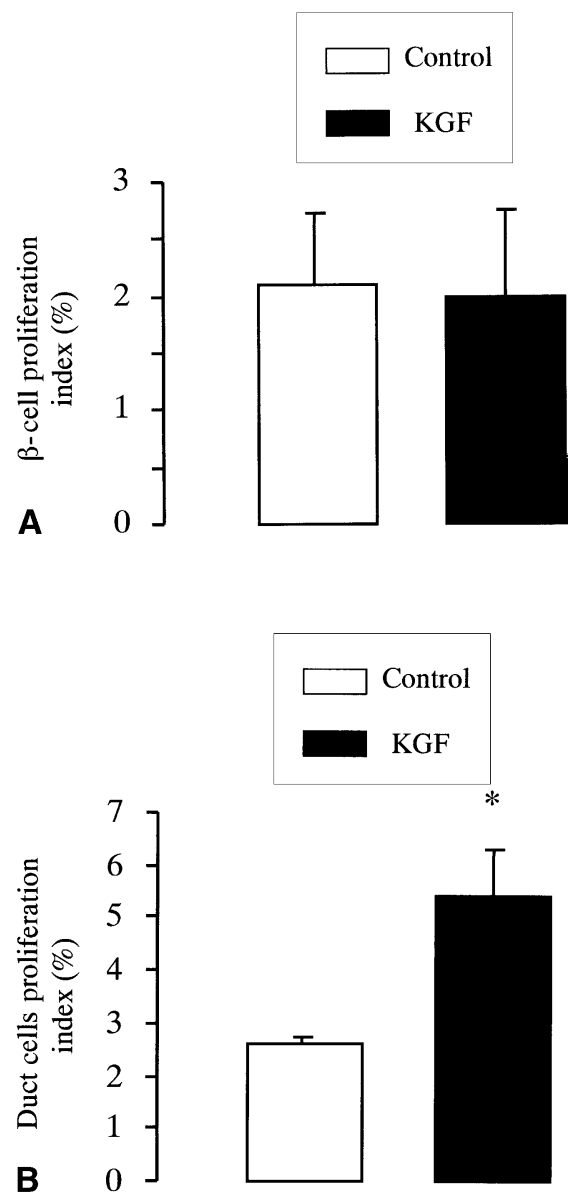

Fig. 4A, B. Beta-cell proliferation index based on Ki-67 and insulin staining performed KGF-treated (dark bar) $(n=3)$ and control graft (white bar) $(n=3) 8$ weeks after transplantation. At least 800 beta cells were counted per graft. Statistical comparison showed no difference between the two groups. B Ductalcell proliferation index estimated on graft sections stained for Ki-67. At least 400 ductal cells were counted per graft. Statistical comparison showed a significant increase of ductal cell proliferation in the KGF treated group (dark bar) $(n=3)$. $p<0.05$

\section{Discussion}

Data provided by this study indicate that KGF positively regulates the expansion of human fetal beta cells in vivo. The keratinocyte growth factor, a member of the fibroblast growth factor family stimulates the proliferation of epithelial cells in vitro and also regulates the proliferation and differentiation of a variety of epithelial tissues in vivo $[14,15,16]$. In the pancreas, previous works have shown the effect of KGF in ductal-cell proliferation [5]. The expression of this growth factor and its receptors is up-regulated in pancreatic carcinomas [17]. Studies in transgenic mice expressing KGF alone [18] or both KGF and EGF [19] in their beta cells showed that ectopic expression of KGF in the pancreas induces increased ductal-cell proliferation, profound changes in pancreatic morphology and the appearance of hepatocytes within the islets. Our findings provide clear evidence of a growth promoting effect of KGF when given parenterally on human fetal beta cells. In this study, daily administration of KGF during 10 days induced a statistically significant increase in the number of beta cells within grafts containing human fetal endocrine precursor cells. Moreover the newly differentiated beta cells were functionally competent as shown by their responsiveness to glucose. Rats treated with $\mathrm{KGF}$ showed concentrations of human C-peptide that rose after glucose administration, while in the control rats the insulin secretion was not stimulated by glucose, a known characteristic of the functionally immature human fetal beta cell. We have also carried out a glucose stimulation test in both groups of animals 4 weeks after the beginning of the treatment. Of interest, the human fetal beta cells in KGF-treated rats were already responsive to glucose at this early stage as evidenced by the stimulation of insulin secretion. In contrast, in the control group the concentrations of human $\mathrm{C}$-peptide remained unchanged. This indicates that KGF induced a marked acceleration of the mechanism(s) leading to the acquisition of a mature secretory pathway in the newly differentiated beta cells within the transplanted tissue which originally consisted of mainly undifferentiated epithelial cells.

In our in vitro experiments, however, we did not find any positive effect of KGF on the growth of beta cells within the ICCs. After 7 days of treatment, the population of insulin containing beta cells did not increase within the ICCs as evaluated by the measurement of their insulin content per DNA. This suggests that the growth promoting effect of KGF in vivo is mainly caused by an indirect mechanism of action involving activation of complementary biological pathways necessary to the activation of beta cell growth and differentiation. In a recent study we have shown that exendin 4, a long lasting analog of GLP 1, stimulates beta-cell differentiation in vivo but not in vitro [20]. In vitro, in contrast to KGF, exendin 4 exposure induced PDX 1 expression in endocrine precursor cells. The number of cells expressing PDX 1, determined by immunostaining of ICCs sections was similar in both KGF-treated and control group in the present study. The differences observed with the in vitro effect of exendin 4 compared with KGF could be due to the fact that unlike exendin $4, \mathrm{KGF}$ in the absence of other mediators is not able to activate a gene expression cascade leading to PDX 1 expression. We did not investigate the expression of other key molecules in the beta-cell differentiation pathway such as Beta 2/neuroD, HNF3 $\beta$, Nkx6.1, Nkx2.2. Therefore we cannot exclude that KGF treatment in vitro could have exerted an effect on the expression of some of these transcription factors necessary but not sufficient for insulin expression by cells.

The newly formed beta cells in the graft could be generated by replication of existing beta cells and/or 
by differentiation of endocrine precursor cells into beta cells. Previous studies which aimed to examine the participation of these two pathways in the appearance of new beta cells in the graft, using ICCs from human fetal pancreas [13] or neonatal pig pancreas [21] reported that neogenesis of beta cells was present in the former study while both proliferation of existing beta cells and differentiation of ductal cells into beta cells occured in the neonatal pig pancreatic cells. To determine whether KGF acts either by stimulating beta-cell replication or accelerating the differentiation of ductal cells into beta cells, we evaluated the percentage of dividing beta cells in the graft removed from KGF-treated rats and control rats. The data on cell replication showed that the number of mitotic beta cells is not different between the two experimental groups. This suggests that the higher number of beta cells within the grafts treated with KGF was not due to an increase in the proliferation rate of existing beta cells. In contrast, a $(p<0.05)$ mitogenic effect of KGF was evident on ductal cells as shown by a greater percentage of ductal cells stained for Ki-67 in the treated group compared to the control group. In keeping with these results, several authors previously implicated KGF in ductal cell proliferation. In those studies there was evidence of an increased mitotic activity in ductal cells after daily administration of $\mathrm{KGF}$ [5], and a higher percentage of dividing ductal cells in the pancreas of transgenic mice overexpressing KGF [18]. The proliferation and differentiation of pancreatic ductal cells play important roles in experimental models of islet regeneration in rodents [22, 23, 24]. Thus, proliferation of pancreatic duct cells leads to an increase in the number of endocrine precursor cells which could ultimately differentiate into beta cells. Moreover, in pathological states such as pancreatic duct carcinomas, proliferation of ductal cells often leads to islet neogenesis $[25,26]$. In our study, the proliferation index of ductal cells, measured 8 weeks after transplantation was significantly $(p<0.05)$ higher in the KGF-treated group showing the potent mitogenic effect of the growth factor on this cell type. In contrast, medium to large ducts (consisting of more than 30 cells) were more frequently observed in KGF treated grafts. The presence of larger ducts 8 weeks after transplantation suggests that the proliferation of at least some population of duct cells might have been even greater in earlier post transplantation stages, leading to the appearance of large ductal structures at the time of graft examination, 8 weeks after transplantation. The mechanisms of the differentiation of ductal precursor cells into beta cells are not known. We have shown that in vitro activin A promotes beta-cell differentiation in human fetal pancreatic cells [27]. In skin, it has been shown that KGF up-regulates the expression of activin during morphogenesis and wound repair [28]. It is therefore possible that in our experiments KGF might act on beta-cell differentiation at least in part through the stimulation of activin expression.

Another possible mechanism contributing to the increase of beta-cell number in KGF treated grafts is for KGF to act as a survival factor protecting against apoptosis. Recent studies have shown an anti-apoptotic effect of KGF on various tissues such as epidermal cells [29], neural cells [30] and hepatocytes [31]. In this study KGF could have exerted such a role on transplanted cells in the early days after transplantation, a time at which some loss of tissue is known to occur [32]. We did not assess apoptosis in the present work. However the examination of a limited number of graft tissue harvested 3 weeks after transplantation showed the appearance of a small number of endocrine cells in the KGF-treated group at this early stage which were not identifiable in the control group. The limited number of cells in the grafts at this stage did not allow us to carry out quantitative evaluation but the general aspect of the graft suggested that KGF could have exerted such protective effect on the transplanted tissue. In our study, KGF treatment did not alter the growth of native rat pancreatic islets. In our opinion, it is not likely that the discrepancy between the growth promoting effect of KGF in human and rat beta cells could be due to the difference in receptor affinity between rats and humans. Several studies using recombinant human KGF in rat or mouse [33] and amphibians [34] have shown a statistically significant effect of KGF on those cells showing the existence of a high cross-reactivity for KGF and KGF receptor between different species. To explain the absence of a potent growth promoting effect of KGF on adult rat's islets compared to that seen in fetal pancreatic precursor cells in our study, it is interesting to note that it has been previously shown that systemic injection of KGF into adult rats enhanced the ductal cell proliferation without leading to an increased number of endocrine cells [5]. In contrast, when KGF was expressed within the embryonic liver of transgenic mice, pancreatic ductal hyperplasia led to an increased number of insulin-containing ductal cells [35]. The comparison of these two studies suggests a more potent effect of KGF on beta-cell differentiation in fetal pancreas than in the adult which is in keeping with our data. One could explain this in part by the fact that the adult pancreas does contain ductal precursor cells but in the normal situation, duct cells are quiescent [36] However it is evident from different rodent models of pancreatic regeneration in adult, such as partial pancreatectomy in rat [37, 38] or IFN-g transgenic mice [39], that beta-cell neogenesis is stimulated after an increased proliferation of ductal cells. It is hypothesised that in these conditions mature duct cells can transiently regain a more pluripotent phenotype [36] and ultimately differentiate into endocrine cells. Some external stimuli can enhance the endocrine differentiation process $[36,40]$. It is therefore interesting to in- 
vestigate the effect of KGF using the above models of adult pancreas regeneration in which there seem to be a recapitulation of embryonic development. In this situation KGF could be able to efficiently stimulate beta-cell neogenesis in the pancreas.

In conclusion, we provide evidence for a positive regulatory effect of KGF on the expansion of beta-cell mass in transplanted human fetal pancreatic cells. Moreover our results identified the activation of ductal cell proliferation and their subsequent differentiation into beta cells as the main mechanism of action of KGF leading to the expansion of beta-cell mass. Characterisation of the factors able to regulate the growth and differentiation of pancreatic-endocrine tissue has important implications on the outcome of clinical islet transplantation studies.

Acknowledgements. This work was supported by JDRF grant 1-1999-526 and a grant from the Larry L Hillblom Foundation to A. Hayek. J. Movassat was a recipient of a post doctoral fellowship from the "Association de Langue Française pour l'Etude du Diabète et des Maladies Métaboliques."

\section{References}

1. Rubin JS, Osada H, Finch PW, Taylor WG, Rudikoff S, Aaronson SA (1989) Purification and characterization of a newly identified growth factor specific for epithelial cells. Proc Natl Acad Sci USA 86:802-806

2. Housley RM, Morris CF, Boyle W, Ring B, Biltz R, Tarpley JE, Aukerman SL, Devine PL, Whitehead RH, Pierce GF (1994) Keratinocyte growth factor induces proliferation of hepatocytes and epithelial cells throughout the rat gastrointestinal tract. J Clin Invest 94:1764-1777

3. Werner S, Peters KG, Longaker MT, Fuller-Pace F, Banda MJ, Williams LT (1992) Large induction of keratinocyte growth factor expression in the dermis during wound healing. Proc Natl Acad Sci USA 89:6896-6900

4. Ulich TR, Yi ES, Longmuir K et al. (1994) Keratinocyte growth factor is a growth factor for type II pneumocytes in vivo. J Clin Invest 93:1298-1306

5. Yi ES, Yin S, Harclerode DL et al. (1994) Keratinocyte growth factor induces pancreatic ductal epithelial proliferation. Am J Pathol 145:80-85

6. Beattie GM, Levine F, Mally MI et al. (1994) Acid B galactosidase: a developmentally regulated marker of endocrine cell precursors in the human fetal pancreas. J Clin Endocrinol Metab 78:1232-1240

7. Otonkoski T, Beattie GM, Rubin JS, Lopez AD, Baird A, Hayek A (1994) Hepatocyte growth factor/scatter factor has insulinotropic activity in human fetal pancreatic cells. Diabetes 43:947-953

8. Beattie GM, Otonkoski T, Lopez AD, Hayek A (1993) Maturation and function of human fetal pancreatic cells after cryopreservation. Transplantation 56:1340-1343

9. Hinegaedener RT (1971) An improved fluorimetric assay for DNA. Anal Biochem 39:197-201

10. Hayek A, Beattie GM (1997) Experimental transplantation of human fetal and adult pancreatic islets. J Clin Endocrinol Metab 82:2471-2475

11. Lu J, Farrel CL, Aukerman L et al. (1999) Keratinocyte growth factor ameliorates streptozotocin-induced moderate diabetes in rats. Diabetes 48 (Suppl 1):A236
12. Movassat J, Portha B (1999) Beta-cell growth in the neonatal Goto-Kakizaki rat and regeneration after treatment with streptozotocin at birth. Diabetologia 42:10981106

13. Beattie GM, Otonkoski T, Lopez AD, Hayek A (1997) Functional $\beta$ cell mass after transplantation of human fetal pancreatic cells. Differentiation or proliferation? Diabetes 46:244-248

14. Danilenko DM (1999) Preclinical and early clinical development of keratinocyte growth factor, an epithelial-specific tissue growth factor. Toxicol Pathol 27:64-71

15. Potten CS, Booth D, Cragg NJ et al. (2002) Cell kinetic studies in the murine ventral tongue epithelium: mucositis induced by radiation and its protection by pretreatment with keratinocyte growth factor (KGF). Cell Prolif 35 (Supp 1):32-47

16. Finch PW, Rubin JS, Miki T, Ron D, Aaronson SA (1989) Human KGF is FGF-related with properties of a paracrine effector of epithelial cell growth. Science 245:752755

17. Ishiwata T, Friess H, Buchler MW, Lopez ME, Korc M. (1998) Characterization of keratinocyte growth factor and receptor expression in human pancreatic cancer. Am J Pathol 153:213-222

18. Krakowski ML, Kritzik MR, Jones EM et al. (1999) Pancreatic expression of keratinocyte growth factor leads to differentiation of islet hepatocytes and proliferation of duct cells. Am J Pathol 154:683-691

19. Krakowski ML, Kritzik MR, Jones EM et al. (1999) Transgenic expression of epidermal growth factor and keratinocyte growth factor in beta-cells results in substantial morphological changes. J Endocrinol 162:167-175

20. Movassat J, Beattie GM, Lopez AD, Hayek A (2002) Exendin 4 upregulates expression of PDX 1 and hastens differentiation and maturation of human fetal pancreatic cells. J Clin Endocrinol Metab 87:4775-4781

21. Trivedi N, Hollister-Lock J, Lopez-Avalos MD et al. (2001) Increase in beta-cell mass in transplanted porcine neonatal pancreatic cell clusters is due to proliferation of beta-cells and differentiation of duct cells. Endocrinology 142:2115-2122

22. Sharma A, Zangen DH, Reitz P et al. (1999) The homeodomain protein IDX-1 increases after an early burst of proliferation during pancreatic regeneration. Diabetes 48:507513

23. Plachot C, Portha B (2001) Impaired pancreatic duct-cell growth in focal areas of regeneration after partial pancreatectomy in the adult Goto-Kakizaki rat, a spontaneous model of non-insulin dependent diabetes mellitus. Histochem J 33:141-147

24. Sarvetnick N, Shizuru J, Liggitt D et al. (1990) Loss of pancreatic islet tolerance induced by beta-cell expression of interferon-gamma. Nature 346:844-847

25. Terada T, Ohta T, Kitamura Y, Ashida K, Matsunaga Y, Kato M (1997) Endocrine cells in intraductal papillarymucinous neoplasms of the pancreas. A histochemical and immunohistochemical study. Virchows Arch 431:3136

26. Dawiskiba S, Pour PM, Stenram U, Sundler F, AndrenSandberg A (1992) Immunohistochemical characterization of endocrine cells in experimental exocrine pancreatic cancer in the Syrian golden hamster. Int $\mathrm{J}$ Pancreatol 11:87-96

27. Demeterco C, Beattie GM, Atala Dib S, Lopez AD, Hayek A (2000) A role for activin A and betacellulin in human fetal pancreatic cell differentiation and growth. J Clin Endocrinol Metab 85:3892-3897 
28. Beer HD, Gassman MG, Munz B et al. (2000) Expression and function of keratinocyte growth factor and activin in skin morphogenesis and cutaneous wound repair. J Invest Dermatol 5:34-39

29. Jeschke MG, Richter G, Hofstadter F, Herndon DN, PerezPolo JR, Jauch KW (2002) Non-viral liposomal keratinocyte growth factor (KGF) cDNA gene transfer improves dermal and epidermal regeneration through stimulation of epithelial and mesenchymal factors. Gene Ther 9:1065-1074

30. Sadohara T, Sugahara K, Urashima Y, Terasaki H, Lyama K (2001) Keratinocyte growth factor prevents ischemia induced delayed neuronal death in the hippocampal CA1 field of the gerbil brain. Neuroreport 12:71-76

31. Senaldi G, Shaklee CL, Simon B, Rowan CG, Lacey DL, Hartung T (1998) Keratinocyte growth factor protects murine hepatocytes from tumor necrosis factor-induced apoptosis in vivo and in vitro. Hepatology 27:1584-1591

32. Davalli AM, Scaglia L, Zangen DH, Hollister J, BonnerWeir S, Weir GC (1996) Vulnerability of islets in the immediate posttransplantation period. Dynamic changes in structure and function. Diabetes 45:1161-1167

33. Guo J, Yi ES, Havill AM et al. (1998) Intraveous keratinocyte growth factor protect against experimental pulmonary injury. Am J Physiol 275:L800-L805
34. Patrie KM, Kudla AJ, Olwins BB, Chiu IM (1995) Conservation of ligand specificity between the mammalian and amphibian fibroblast growth factor receptors. J Biol Chem 270:29018-29024

35. Nguyen HQ, Danilenko DM, Bucay DM et al. (1996) Expression of keratinocyte growth factor in embryonic liver of transgenic mice causes changes in epithelial growth and differentiation resulting in polycystic kidneys and other organ malformations. Oncogene 12:2109-2119

36. Bonner-Weir S (2000) Islet growth and development in the adult J Mol Endocrinol 24:297-302

37. Plachot C, Movassat J, Portha B (2001) Impaired beta-cell regeneration after partial pancreatectomy in the adult GotoKakizaki rat, a spontaneous model of type II diabetes. Histochem Cell Biol 116:131-139

38. Bonner-Weir S, Baxter LA, Schuppin GT, Smith FE (1993) A second pathway for regeneration of the adult exocrine and endocrine pancreas: a possible recapitulation of embryonic development. Diabetes 42:1715-1720

39. Gu D, Sarvetnick N (1993) Epithelial cell proliferation and islet cell neogenesis in IFN-g transgenic mice. Development 118:33-46

40. Bouwens, Kloppel G (1996) Islet cell neogenesis in the pancreas. Virchows Arch 427:553-560 